\title{
A Perfect Storm
}

For a long time, the Swedish school system, which historically laid the foundation for Sweden's rapid economic transformation from poverty to prosperity, was one of the best and most equitable educational systems in the world. It was arguably at its most successful during the century-long period beginning in approximately 1860 , but even as recently as the midto late 1990s, most Swedish students did well in international comparisons. However, at the end of that period, problems with the quality of Swedish schooling were becoming increasingly apparent. Since then, these problems have grown into a veritable crisis of education.

That crisis has been the main topic of this book. In the early chapters, we reviewed, among other problems, the erosion of students' knowledge across the ability distribution, the increasing practice of grade inflation, and the psychosocial and professional malaise afflicting students and teachers. In later chapters, we examined the institutional evolution of the Swedish school system from the 1960s to the 1990s. We showed how a classical view of knowledge and teaching was replaced by a postmodern social constructivist view in both national curricula and individual subject syllabi. This new view does not recognize the existence of objectively established and interpersonally transferable facts.

This major change in the stipulated view of knowledge-arguably, as we suggested in Chapter 5, the single most important institution for the functioning and development of any school system-coincided and interacted with a phase of organizational fragmentation. In as little as five 
years, 1990-1994, the Swedish school system went from being highly centralized and regulated to becoming radically decentralized and market driven. Most importantly, for-profit schools were allowed to compete against public schools for students' educational vouchers.

In this chapter, in which we allow ourselves to be more normative and reflective, we assemble the pieces and discuss how the combination of a postmodern social constructivist view of knowledge and marketized education created a perfect storm that set the present crisis in the Swedish school system in motion and continues to propel it. We do this in three parts. First, we discuss academic performance and grade inflation. Then, we look at the health and attitudes of the students. Finally, we discuss the unattractiveness of the teaching profession.

The next chapter will spell out the larger implications of the book and point to what we believe are the most important lessons from our analysis not only for Sweden but also for Western elementary and secondary education in general.

\section{The Decline in Knowledge and Rise in Grades}

To explain the incongruous evolution of results in both national and international assessments of students' knowledge and Swedish grades, we begin by returning to our main argument that the view of what constitutes knowledge and how it should be obtained has gradually shifted in the school system. As documented most fully in Chapter 6, the classical view of knowledge as a set of systematically accumulated and verifiable facts that can be taught to and learned by any person-as well as different types of skills that are grounded in factual knowledge and human experience-was increasingly called into question during the second half of the twentieth century. ${ }^{l}$ Eventually, it was supplanted by a postmodern social constructivist view of knowledge and pedagogy.

After the teachers' resistance was broken down-a gradual process that was largely completed in the early to mid-1990s - this reorientation of focus from imparting knowledge in the classical sense to student-centered learning and deconstructive classroom discussions would in itself have

${ }^{1}$ The term "facts" is here used as shorthand for the broad communal knowledge that individuals, according to the classical view of knowledge, must acquire in order to fully take part in and help renew the society that they have been born into. See our discussion in Chapter 5. 
been enough to impair the students' knowledge acquisition and weaken their results on national and international tests. As demonstrated in Chapter 5, the pedagogy emanating from the postmodern social constructivist view of knowledge goes against empirically proven prerequisites for efficient learning. Further support for this assertion is provided by experiences in other comparable countries and societies. Several of them have recently abandoned their classical curricula for a postmodern social constructivist educational philosophy, which has resulted in sizeable drops in academic performance. (We will return to this issue in the final chapter.)

However, it is unlikely that the decline would have been as severe, or that students' grades would have begun to rise almost simultaneously, if it had not been for the influence of other factors as well-particularly the decentralization and marketization of the Swedish school system, described at length in Chapter 7.

Productive firms and other successful organizations are highly dependent on structural capital in the form of embedded processes, procedures, and methodologies, and the building of such capital is an arduous, incremental process. ${ }^{2}$ By comparison, in 1990, 290 Swedish municipalities, the smallest of which comprised no more than three thousand inhabitants, were expected to create their own governance structures and rules for education management. They were expected to achieve this complex task in less than one year and do so without any hands-on support or guidance from the central government and its agencies. This was not only unrealistic but also unwise, creating a fractured and debilitated institutional environment for schools. Crucially, there was no longer a national regulatory agency tasked with supervising schools. The task of the newly formed Swedish National Agency for Education-staffed by civil servants sympathetic to postmodern ideas-was, instead, merely to document and disseminate "good examples."

In effect, this amounted to a policy of self-regulation for schools. Around the same time, in 1992-1993, the so-called free school reform converted elementary and secondary education into a contestable quasimarket. Students and parents were given vouchers amounting to 100 percent of the average cost per student in public schools to use in any

${ }^{2}$ For further information, see Nelson and Winter (1982) and Teece (2007). 
school of their choice, ${ }^{3}$ while the production side was opened to virtually any nonprofit or for-profit organization that wanted to run an independent school. The political vision was that a plethora of passionate school actors would crop up. However, in reality, large for-profit firms quickly came to dominate education provision in Sweden.

The almost complete lack of nongovernment, nonprofit providers of welfare services, including education, in Sweden may seem surprising to an outside observer. One likely reason for this state of affairs is that notions of selfless service and reciprocity between citizens have been phased out jointly by the Left and Right. ${ }^{4}$ To put it somewhat simply, the particular variant of left-wing ideas about liberating ordinary people from various perceived social and economic "oppressors" that came to predominate in Sweden was that of the Social Democrats, for whom the means of liberation was statist individualism. ${ }^{5}$ Reciprocal obligations within the family, between friends, and within communities were systematically weakened and replaced by a reciprocal contract between the individual and the public sector that provided the individual with income security and social services. ${ }^{6}$ The Right did not object to this policy. To avoid upsetting the Left's acceptance of individualism, the Right refrained from arguing for the complementary components necessary to sustain individual freedom, such as a sense of duty and civic mindedness. ${ }^{7}$ This has resulted in a lack of cultural and institutional contexts in which alternatives to state and for-profit organizations can emerge and thrive. This differs markedly from, for instance, Wisconsin, where small-scale religious schools have come to dominate the voucher program, as noted in the previous chapter.

A chief motivation behind the free school reform was, in any case, to improve educational quality through competition and consumer choice.

${ }^{3}$ Until 1996 the voucher amounted to 85 percent of the average cost per student in public schools.

${ }^{4}$ For further discussion of Left-Right convergence in Sweden, see Wennström (2019).

${ }^{5}$ Berggren and Trägårdh $(2006,2011)$.

${ }^{6}$ This is also described at some length in Lindbeck (1988). Lindbeck (1997) makes the following observation: "Whereas production firms were socialized in socialist countries, the Swedish welfare state has instead, to a broad extent, socialized the provision of personal services to individuals and families."

${ }^{7}$ For a discussion of the Right's abandonment of conservative principles, see Hylén (1991). 
However, it is uncertain whether it is possible to transplant mechanisms that in most cases work well in ordinary markets to raise the quality of publicly funded welfare services - thereby creating a quasi-marketand obtain the desired result. For instance, the scope for the misuse of resources and even abuse increases when an anonymous third party, i.e., the taxpayer, finances all transactions between producers and consumers. ${ }^{8}$

Moreover, and more importantly, welfare services such as education are credence (or trust) goods whose value consumers are not able to fully assess on their own. Therefore, these goods are particularly susceptible to manipulation by producers. ${ }^{9}$ This suggests that in regard to privatization and competition in welfare production, it is vital to have regulatory frameworks and incentives that promote moral behavior among producers. ${ }^{10}$ In the case of the marketized provision of education, there must be institutions in place that favor those schools that wish to compete in educational quality and not in other dimensions. As Frederick M. Hess, an education scholar at the American Enterprise Institute, points out, "[ $t]$ he notion that charter school laws or voucher programs will inevitably spur the creation of good schools and programs is misleading. After all, we know that vacuums are not naturally or automatically filled by effective or virtuous actors."11

A vacuum was indeed created in Sweden when the old governance structure was dismantled and replaced by the decentralized management of schools. The last vestiges of central regulatory control over education disappeared in 1994, when a new, slimmed down curriculum and a wholly teacher-assessed grading system, both heavily influenced by the postmodern social constructivist view of knowledge, were implemented. With these changes, there were suddenly no national standards for what students needed to know and be able to do in core subject areas and no way of ensuring fair and equitable grading across schools.

The stage was now set for schools to begin offering inflated grades, ultimately motivated by the fact that revenue for both public and independent schools was, and still is, directly related to the size of their student bodies. (The alternative in regular markets, of charging a higher

\footnotetext{
${ }^{8}$ See further Le Grand (2007).

${ }^{9}$ Dulleck and Kerschbamer (2006).

${ }^{10}$ Hodgson (2013) and Nooteboom (2014).

${ }^{11}$ Hess (2008, p. 212).
} 
fee for a superior service, is not possible in the quasi-market model.) The evidence suggests that this is exactly what happened and that independent schools took the lead early on. ${ }^{12}$ One study of how competition among Swedish secondary schools functioned in 1997, a mere three years after the 1994 grading and curriculum reforms, found that "independent schools seriously engage in grade inflation" and that "students in independent schools appear to fare much better under decentralized grade setting than in the public schools."13

Contrary to the predictions of school voucher proponents, consumer choice was no guarantee for improved quality. The use of grade inflation by independent schools during the infancy of the school market, made possible (and even rational) by the lax institutional framework, was clearly appealing to more than just a few consumers of education. Initially, it may have been the case that some parents and students could not afford to complain about inflated grades, while others who were less scrupulous took advantage of the situation. Over time, however, a preference for good grades in return for little effort likely emerged on a wider scale. Changing social norms concerning the value of educational achievement might have contributed to such a development. In fact, appreciation of hard work and academic tenacity tends to decrease in wealthy and highly modernized welfare societies. ${ }^{14}$ Increasingly, academic credentials are not even expected to reflect the possession of knowledge per se but are rather seen as information about the individual's productivity. ${ }^{15}$ The market setting itself may also have created a "moral disengagement" and reduced the salience of fairness in the minds of parents and students, as suggested by experiments conducted in economics that demonstrate the "corrosive effect of markets" on ethical reasoning. ${ }^{16}$ In any case, public schools, as well as independent schools with high academic standards, were forced to gradually adapt to remain competitive.

${ }^{12}$ This still appears to be true today. According to Vlachos (2019) all categories of independent schools, particularly schools belonging to two of the largest corporate groups, have higher teacher-set grades than public schools at the elementary level, and this advantage for students can be accounted for by considering their more lenient grading practices.

${ }^{13}$ Wikström and Wikström (2005, p. 317).

${ }^{14}$ For further information, see Heller Sahlgren (2015b), Lindbeck and Nyberg (2006).

${ }^{15}$ Caplan (2018).

${ }^{16}$ Bowles (2016, p. 112). 
Through this market process, education in Sweden came to be increasingly concerned with generous grading while progressively pushing the traditional goal of imparting knowledge and skills into the background. It is somewhat ironic that postmodernism's professed educational goal of training students to unmask and destabilize power has not been prioritized in the school system it helped to create. In contrast, it seems that perhaps the chief contribution of the postmodern social constructivist view of knowledge to the Swedish school system has been to facilitate the emergence and gradual entrenchment of a crass form of capitalism.

As these problems became increasingly apparent toward the end of the 2000s, the central government and its agencies responded by taking a series of measures. However, the remedial measures turned out to be largely inefficient because they did not eliminate the fundamental cause of the identified problems, namely, the postmodern social constructivist view of knowledge. Rather, they built on this view of knowledge. The switch in 2011 to a new national curriculum, which included more detailed course syllabi and grading criteria for each school subject, should, for instance, have ensured a greater degree of consistency in education across schools and reduced the undesired effects of school competition. However, it did not, because the new curriculum was, as we demonstrated in the previous chapter, just as influenced by the postmodern social constructivist view of knowledge as the previous curriculum.

Moreover, following the ill-advised introduction of a flawed system of national certification for teachers in 2013 (the details of which will be discussed below in the section on the teaching profession), the government decided that only certified teachers would be allowed to set grades. This change stemmed from the fact that neither public nor independent schools were obligated to hire teachers who had been formally trained as elementary or secondary school teachers, and it was an attempt to bring more rigor to the grading process. However, teachers who were certified in one subject were given permission to set grades in every other subject as well if the person responsible for teaching that subject was not certified. The official motivation for this rule was that "grade setting is considered to be a global competence held by all certified teachers," who, therefore, were not even required to "participate in the subject-specific teaching or independently gather information for grade assessment." ${ }^{17}$ This system

${ }^{17}$ Swedish National Agency for Education (2020). 
bore all the hallmarks of the postmodern social constructivist view of knowledge and, consequently, did not bring more rigor to grading. ${ }^{18}$

In contrast, it may have provided new opportunities for conflicts over grades, as parents and students can sometimes bring their complaints about low grades to other teachers. It also provided a new opportunity for fraudulent behavior by schools. In certain circumstances under the new certification system, the school principal may set grades-which is potentially hazardous because the professions of teachers and principals have become increasingly separated, and today's principals "have become middle managers responsible for their school's survival in the school market." 19

\section{The Students (and Boys)}

In Chapter 4, we noted several signs of something being not quite right with how Swedish students are developing and coping at school. First, there are large gender disparities in academic achievement; regardless of the comparison lens, boys underperform relative to girls. Widespread antidemocratic attitudes among students and an inability to distinguish between credible news sources on the one hand and propaganda and advertisement on the other suggest impaired moral reasoning and weak critical thinking skills among a significant proportion of students. Moreover, there are increasingly clear signs of a general social disorder in many schools that negatively impacts students' sense of safety and well-being as well as their chances of learning. The incidence of mental health problems among students has also risen. As with the problem of grade inflation, the evidence points to a combination of the market forces and the postmodern social constructivist view of knowledge that has evolved in the Swedish school system as the source of this issue.

As we have documented, the fall in both PISA and TIMSS has been greater among boys than girls. In addition, girls, on average, receive higher grades in every subject than boys do. Interestingly, their parents'

\footnotetext{
${ }^{18}$ The notion of a "global competence" in grade setting is congruent with the postmodern social constructivist view that there is no established body of knowledge in which a teacher can become an expert and that clear boundaries between disciplines lack legitimacy. This idea is also in line with the view of skills, e.g., critical thinking, as generic and not domain specific.
}

${ }^{19}$ Jarl, Fredriksson, and Persson (2012, p. 434). 
level of education does not seem to matter-even among children of parents with the highest level of education, girls academically outperform boys. The only possible explanation for these facts is that boys are somehow disadvantaged relative to girls in the Swedish school system. In our view, the disadvantage in question is that postmodern social constructivist pedagogy is generally less harmful to girls than to boys.

The extensive available knowledge of male-female genetic differences suggests that males and females, on average, can accomplish most intellectual tasks equally well despite varying choices and uses of cognitive tools. The evidence also shows that females possess, among other abilities, superior verbal skills and tend to rely on them in solving intellectual problems. In contrast, males have been shown to have advantages in visuospatial abilities and the extremes of mathematical ability. ${ }^{20}$ Against this background, it is not difficult to imagine what will happen to boys who are placed in a postmodern social constructivist school system such as Sweden's, in which the emphasis - even in rigorous and hard subjects such as physics and mathematics - is strongly focused on verbal discussion and word problems rather than learning specific solutions by practice and repetition. In such a context, boys will fall behind and learn less than girls. Consequently, boys will, as they do in Sweden, also perform relatively worse in reading comprehension. As discussed in Chapter 5, reading comprehension is a domain-specific skill.

Additionally, girls have an advantage in obtaining good grades within Sweden's postmodern social constructivist school system. Because females are generally better at social cognition or empathy than males, ${ }^{21}$ girls will be better at "gaming" the vague grading criteria than boys are, i.e., determining what teachers read into the criteria and meeting that subjective standard (rather than improving their understanding of the subject). It is also possible that girls are more skilled than boys at negotiating a higher grade because of their social advantages - which Swedish students, as we have shown, are empowered to do due to both the grading instructions and the market setting of the school system. The empirically documented grading bias against boys in the Swedish school system-which would not have emerged with clearly defined grading criteria, and which was not

\footnotetext{
${ }^{20}$ See, e.g., Halpern et al. (2007) and Scheiber et al. (2015). Murray (2020, Chs. 1-5) is a recent extensive effort to synthesize the evidence on male-female differences in a wide spectrum of personality traits as well as physical abilities.

${ }^{21}$ See, e.g., Kret and De Gelder (2012) and Gur et al. (2012).
} 
present in the previous grading system-might also be associated with this difference in social ability.

The fact that a significant portion of younger Swedes currently or recently involved in the school system are opposed or indifferent to democracy, willing to sell their vote, and support political candidates who promise them paid jobs represents the very opposite of what Swedish policymakers hoped to achieve with their education reforms after World War II. However, it is a predictable outcome of the postmodern social constructivist school system that these policymakers laid the foundations for by discouraging an education that imparts communal knowledge, including such knowledge and ethical concepts that have been deemed essential in the national context. In the old elementary school system, the folkskola, the development of the rule of law and the history of democratic advancement in Sweden were vividly and even movingly conveyed to students. ${ }^{22}$ However, increasingly, students in the new school system are expected to discover their own knowledge and even their own values. ${ }^{23}$ When the school system was eventually marketized, there remained few incentives for students to consider the common good and communal priorities. In fact, through the escalation of grade inflation, they were essentially taught not to transcend their narrow self-interest or to consider the interests of others. It is thus only logical that Swedish students as a whole do not exhibit a greater appreciation for democratic norms and practices.

Similarly, it is not at all surprising that many students develop only weak critical thinking skills and are unable to separate unbiased information from commercial and politicized messages. Skills, to return again to the discussion in Chapter 5, are generally domain specific and not universal. Critical thinking is not an exception-meaning that to exercise critical thinking in various subjects, a person needs to be well read and broadly knowledgeable. However, due to its postmodern and marketoriented principles, the Swedish school system effectively eliminates this prerequisite for critical thinking and, indeed, many other vital skills by

\footnotetext{
${ }^{22}$ See, e.g., Rosén and Jonsson (1954).
}

${ }^{23}$ We can add to what we have already written in Chapters 6 and 7 the following from a 1975 government bill on priorities in Swedish elementary education: "The goal ... can be said to be that the individual successively reaches his or her own conclusions about what values and norms he or she eventually wishes to uphold and live by" (Government Bill, 1975/76:39, p. 68). 
not focusing on imparting knowledge in the classical sense. Thus, if schools would return to teaching students the basics of every subject, then students' ability to think critically would also be enhanced.

Another important goal of the postwar education reforms in Sweden was to improve students' well-being at school and develop their social skills. However, as we have shown, the Swedish school system has become blighted by violence and rule-breaking behavior, making classrooms increasingly disorderly and unsafe. This, too, is an expected consequence of the amalgamation of postmodernism and neoliberalism; due to the institutionalized claim that teachers' authority is just an arbitrary expression of power in combination with marketized demands for parental and student influence, it has become almost impossible for schools to suspend students or impose any other sanction. This has already been mentioned in Chapter 7, but we add here that the Child and School Student Representative (an arm of the Swedish Schools Inspectorate) has in some cases even ordered financial compensation for unruly or threatening students who have been temporarily expelled from their school. Students who lack empathy and concern for others will thus feel that they have been given free rein by their schools to do almost anything.

For a large group of students, however, the source of their delinquent habits (truancy, milder forms of classroom disturbances, late arrivals, etc.) may be frustration with the schoolwork itself. Even if students accept inflated grades, the relegation of education to a mere competition for high grades blocks genuine creativity and intellectual effort, which are the very qualities of education that make students concentrate and apply themselves. We have also previously pointed out (in Chapter 5) that a postmodern social constructivist pedagogy - in which students are left to discover and piece together information on their own-risks overloading students' working memory. As a result, a previously quoted study explains, "focus is lost, the mind wanders, and the task is abandoned." 24 This may constitute an additional factor behind the increase in delinquency-particularly as students in core subjects such as mathematics are made to work an increasing number of hours but without a change from the teaching methods that generated the frustration in the first place. ${ }^{25}$ As

\footnotetext{
${ }^{24}$ Dehn $(2014$, p. 497).
}

${ }^{25}$ In order to improve students' poor mathematics achievement, more than 300 additional hours of mathematics have been prescribed in elementary school. However, according to all measures of student performance in mathematics, the added hours have 
noted in the 1955 national curriculum for the folkskola, ${ }^{26}$ enacted when care was taken to adapt teaching methods to human nature, "[n] othing can be more designed to produce hopelessness and weariness with one's schoolwork than a daily reminder of one's own ineptitude"-but that is exactly what many students are experiencing.

While some students' response to this environment is delinquent behaviors, others may develop psychological problems. As we showed in Chapter 4, diagnoses of depression and anxiety among children and teenagers have soared, as have the prescriptions for ADHD drugs. Levels of stress have also risen significantly among students, particularly among girls. A postmodern social constructivist pedagogy is not the only factor at play here ${ }^{27}$ but it is certainly an important one. Hyperactivity, anxiety, and feelings of low self-esteem (as well as physical aggression) increased among Québecois students relative to students in the rest of Canada following a postmodern social constructivist reform in Québec in the early 2000 s that was similar to the Swedish pedagogical reforms. ${ }^{28}$ We may, therefore, assume a similar causal, contributory role of the postmodern social constructivist view of knowledge in the mental health crisis among students in Sweden.

\section{The Teachers: The Vicious Circle}

As we have seen in previous chapters, explicit teacher instruction plays a central role in student learning. Since the teacher is so important, one would expect that the profession would more or less automatically be held in high social regard. However, as we discussed in Chapter 4, this is not

had no effect whatsoever. In fact, the mathematics results have even declined since this reform was instituted (Lindstrand, 2021), suggesting that the problem is the way mathematics is taught rather than the amount of time dedicated to teaching it.

${ }^{26}$ Swedish National Board of Education (1955, p. 11).

${ }^{27}$ As suggested by Lukianoff and Haidt (2018) in the U.S. context, the spread of social media and smartphones into the lives of teenagers may have contributed to the rapid rise in rates of anxiety and depression among American adolescents, particularly girls, during the 2010s. While we can only speculate about this, it does not seem implausible that a combination of postmodern social constructivist pedagogy overloading students' working memory during school hours and the heavy presence of social media and smartphones in the students' free time may, in the Swedish context, help explain the rise in mood disorders.

${ }^{28}$ Haeck, Lefebvre, and Merrigan (2014). 
the case in Sweden, where the status of teachers has been declining for a long time and education degree programs have great difficulty attracting and retaining motivated and academically gifted students.

Various superficial reasons are often given for this state of affairs. Arguably the most common is the bureaucratization and proletarianization of the teaching profession that occurred after the introduction of the market-oriented NPM model of control and accountability into the Swedish school system in the early 1990s. However, that introduction did not happen on its own; NPM, in fact, became necessary when teachers abandoned their old public-service ethos for a material and self-interested conception of work-and that, in turn, would not have happened if teaching in the classical sense and the traditional values of teachers had not been aggressively and openly undermined for decades by governments on both the left and right. ${ }^{29}$ Thus, the emergence of NPM in schools is just one of many examples demonstrating that the real reasons for the unattractiveness of the teaching profession have to do with the postmodern social constructivist view of knowledge. The previous section suggests that violence in schools directed at teachers may also be counted among these examples.

Let us again briefly look at what the postmodern social constructivist view of knowledge entails and how it plays out in the Swedish school system. Most importantly, this view contends that there is no such thing as objective and empirically verifiable knowledge specific to various fields and accessible through systematic study directed by competent teachers. Claims to the contrary are seen as inherently biased and ideological. Hence, the classical model of teacher-directed learning is considered to be, at best, ineffective and, at worst, oppressive. Pedagogical practice based on the postmodern social constructivist view of knowledge instead transfers the responsibility for learning to the students themselves, while the teacher is, for the most part, relegated to a mentoring and advisory role.

These principles loom large in the Swedish national curriculum, in which the content of each subject is only vaguely formulated, and it is explicitly stated that education should be organized to enable as much

${ }^{29}$ As observed by Lopes $(2018$, p. 117), "the perception that authority is illegitimate, or that the employer is disloyal, may damage the perceived meaningfulness of work." For a further discussion of how teachers become demoralized by value conflicts with pedagogical policies, see Santoro (2018). 
adjustment as possible to the students' (and, by extension, their parents') subjective wishes and choices. All this undercuts the teacher's basis for making demands and having expectations regarding student effort. Any remaining status for teachers as an authority figure is lost when students in many subjects are encouraged to collaboratively deconstruct and criticize "power." Thus, instead of openly demonstrating his or her knowledge and skills and offering them to the students, the teacher must deprecate and implicitly apologize for his or her professional role.

In the postmodern social constructivist view of knowledge, grades and other forms of assessment become controversial because, according to this view, there is no objective way to measure what students know. However, grades constitute the prime selection instrument for secondary education and universities in Sweden and cannot be done away with. The "solution" to this dilemma has been to formulate as loose and arbitrary a set of grading criteria as possible, focus on evaluating individual students' learning processes based on a number of indicators and in this way arrive at a grade. In practice, this is done by evaluating various technical or mechanical aspects of students' performance in a subject, which themselves are difficult to measure objectively, based on so-called knowledge matrices. Two examples of such matrices are presented in Appendix B.

The drawback of this is that grade setting de facto becomes a subjective expression of power according to the postmodern social constructivist view of knowledge and can be criticized both by students and parents and by school principals who want to use generous grading as a means to attract students, who are, in effect, customers. Nevertheless, the teacher is obliged to assign grades to the detriment of what remains of his or her professional honor and integrity.

Ultimately, this means that a teacher has little of value to contribute, which is something future teachers come to realize during their training. Figure 8.1 summarizes the various components of this detrimental process that result in the low status of the teaching profession, which manifests itself in the form of a high dropout rate from teacher-training programs and a high number of active teachers leaving the profession. Recent remedial measures to raise the status of the teaching profession in Sweden have done virtually nothing to change this, since they have not included a break with, or at least a mitigation of, the influence of the postmodern social constructivist view of knowledge.

Consider, for instance, the system of national certification for teachers that was enacted in 2013, which we mentioned in the context of grading 


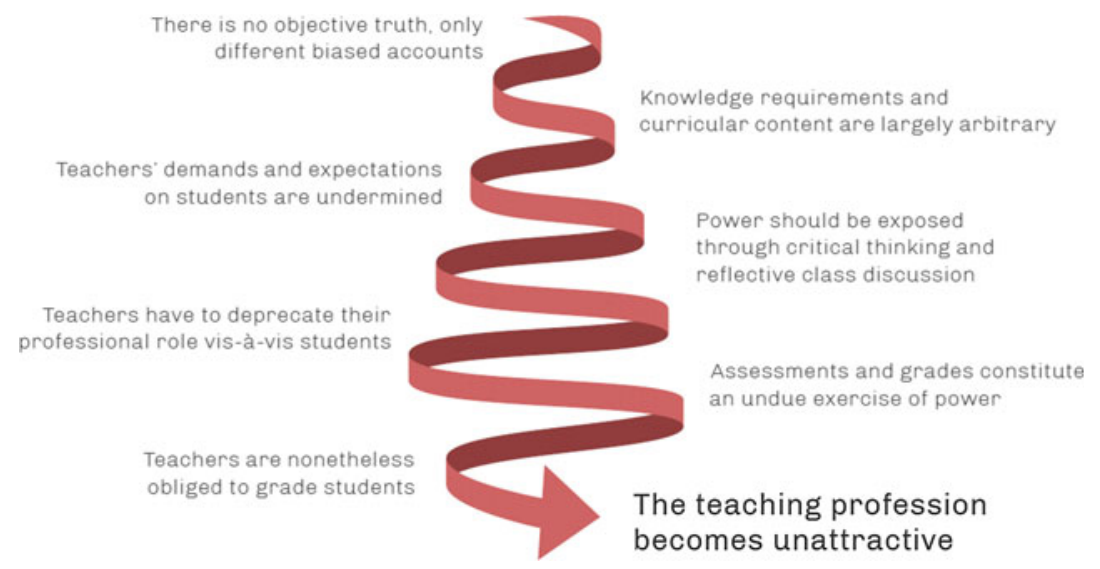

Fig. 8.1 The status of the teaching profession: the vicious circle

above. ${ }^{30}$ Those who had taught a subject for at least eight years became certified even if they had never studied the subject themselves. Moreover, leisure-time pedagogues were given generous opportunities to become certified to teach in elementary school without having relevant collegelevel training. The same year, the government also introduced a new teacher position, that of primary teacher (förstelärare). Promotion to primary teacher was intended to be open to particularly excellent teachers and came with a pay increase of at least 15 percent. However, eligibility was not tied to any formal criteria, such as having a Ph.D. degree. Thus, school principals could use this instrument at will. (Primary teachers who decided to step down from that position and the additional obligations still retained the pay raise.) In both cases, it was not deemed important to ensure that teachers ostensibly deserving of more respect from colleagues and society were in possession of formal qualifications and subject-specific knowledge.

${ }^{30}$ When this reform was introduced, the government was taken aback by the large share of teachers lacking formal qualifications. It turned out that almost 50 percent of all teachers either lacked formal qualifications altogether or had gone through teacher training but taught subjects other than those they were trained for. The government, therefore, felt forced to introduce a number of exceptions. However, these exceptions would never have been designed the way they were if not for the influence of the postmodern social constructivist view of knowledge. 
This critique of how teaching works today does not imply that everything was perfect and that all teachers were excellent before the postmodern social constructivist view of knowledge became predominant. However, school results were much better at that time than they have been since the radical change in the view of knowledge and the application of the pedagogical theories that motivate the new ways of learning. Teachers were previously trained in, and applied, techniques proven to be efficient in imparting knowledge to students and in helping students consolidate that knowledge. As we will argue in the final chapter, this is what Sweden, and indeed the West, must rediscover.

Open Access This chapter is licensed under the terms of the Creative Commons Attribution 4.0 International License (http://creativecommons.org/licenses/ by $/ 4.0 /)$, which permits use, sharing, adaptation, distribution and reproduction in any medium or format, as long as you give appropriate credit to the original author(s) and the source, provide a link to the Creative Commons license and indicate if changes were made.

The images or other third party material in this chapter are included in the chapter's Creative Commons license, unless indicated otherwise in a credit line to the material. If material is not included in the chapter's Creative Commons license and your intended use is not permitted by statutory regulation or exceeds the permitted use, you will need to obtain permission directly from the copyright holder.

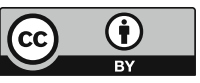

